\title{
STUDYING THE STRUCTURE AND PROPERTIES OF ELASTOMERIC COMPOSITES DESIGNED TO OPERATE UNDER EXTREME CONDITIONS
}

\author{
V. V. Portnyagina*, N. N. Petrova, N. P. Ovchinnikov, A. N. Martynova \\ M.K. Ammosov North-Eastern Federal University, \\ 58 Belinskogo St., Yakutsk, 677000, Russia \\ *Corresponding author. E-mail: vick_i@mail.ru; \\ address for correspondence: 677000, Yakutsk, ul. Kulakovskogo, 46. \\ Tel.: 8(4112) 3675 69; fax: 8(4112) 367569
}

The paper presents results of studying the main operational properties and structure of sealing rubbers based on propylene oxide rubber and ultrafine polytetrafluoroethylene intended for extreme operating conditions. It is shown that, to achieve a positive effect on the material properties, it will suffice to add to the rubber compound $0.5-1 \mathrm{wt} \%$ of polymer per $100 \mathrm{wt} \%$ of rubber. This is due to the high activity of UPTFE particles, their nanostructured arrangement and better uniformity of their distribution in the volume of the elastomeric matrix. RF and US patents for rubber formulations have been taken out.

Keywords: sealing materials, propylene oxide rubber, ultrafine polytetrafluoroethylene, frost resistance, wear resistance, structure of elastomeric material, electron microscopy.

DOI: $10.17804 / 2410-9908.2017 .2 .034-039$

\section{References}

1. Chersky I.N. Polimernyie materialy $v$ sovremennoy uplotnitelnoy tekhnike [Polymeric Materials in Modern Sealing Technology]. Yakutsk, Knizhnoe izdatelstvo Publ., 1975, 110 p. (In Russian).

2. Govorova O.A., Vishnitsky A.S., Chubarova G.V., Morozov Yu.L. Development of weather-resistant rubbers with improved low-temperature and adhesive properties. Kauchuk $i$ rezina, 1999, no. 2, pp. 18-20. (In Russian).

3. Petrova N.N., Portnyagina V.V., Biklibaeva R.F. Wear-Resistant Mixture Based on Propylene Oxide Rubber. RF Patent 2294346, 2007. (In Russian).

4. Buznik V.M., Fomin V.M., Alkhimov A.P. Metallopolimernye nanokompozity [Metalpolymer nanocomposites]. Novosibirsk, Izd-vo SO RAN Publ., 2005, 260 p. (In Russian).

5. Petrova N.N., Portnyagina V.V. Rubbers based on mixtures of propylene oxide rubber and polytetrafluoroethylene. Kauchuk i rezina, 2007, no. 4, pp. 8-11. (In Russian).

6. Kuleznev V.N. Smesi polimerov [Polymer Mixtures]. Moscow, Khimiya Publ., 1980, 304 p. (In Russian).

7. Van Krevelen D.W. Svoistva i khimicheskoe stroenie polimerov [Properties and Chemical Structure of Polymers]. Moscow, Khimiya Publ., 1976, 414 p. (In Russian).

8. Petrova N.N., Portnyagina V.V. Wear-resistant rubber based on propylene oxide rubber and ultra-fine polytetrafluoroethylene. RF Patent 2502759 C1, 2013. (In Russian).

9. Petrova N.N., Portnyagina V.V. Wear-resistant rubber based on propylene oxide rubber and ultrafine polytetrafluoroethylene, US Patent 8841370 Bl, 2013. 
Подана в журнал: 01.07.2017

УДК 678.7

DOI: $10.17804 / 2410-9908.2017 .2 .034-039$

\title{
ИССЛЕДОВАНИЯ СТРУКТУРЫ И СВОЙСТВ ЭЛАСТОМЕРНЫХ КОМПОЗИТОВ ДЛЯ ЭКСТРЕМАЛЬНЫХ УСЛОВИЙ ЭКСПЛУАТАЦИИ
}

\author{
В. В. Портнягина*, Н. Н. Петрова, Н. П. Овчинников, \\ А. Н. Мартынова \\ Северо-Восточный федеральный университет им. М.К. Аммосова, \\ ул. Белинского, 58, Якутск, Россия \\ *Ответственный автор. Электронная почта: vick_i@mail.ru; \\ адрес для переписки: 677000, г. Якутск, ул. Кулаковского, 46. \\ Тел: 8 (4112)36-75-69; факс: 8(4112) 36-75-69
}

Представлены результаты исследования основных эксплуатационных свойств и структуры уплотнительных резин на основе пропиленоксидного каучука и ультрадисперсного политетрафторэтилена для экстремальных условий эксплуатации. Показано, что для достижения положительного влияния на свойства материала в резиновую смесь достаточно ввести 0,5-1 мас. ч. полимера на 100 мас. ч. каучука. Это связано с высокой активностью частиц УПТФЭ, их наноструктурной организацией, лучшей равномерностью их распределения в объеме эластомерной матрицы. На рецептуры резин получен патент РФ и США.

Ключевые слова: уплотнительные материаль, пропиленоксидный каучук, ультрадисперсный политетрафторэтилен, морозостойкость, износостойкость, структура эластомерного материала, электронная микроскопия.

\section{1. Введение}

Разработка полезных ископаемых в северных регионах Российской Федерации требует создания новых уплотнительных эластомерных материалов для экстремальных условий эксплуатации. Эластомерные материалы уплотнительного назначения, которыми комплектуются управляющие, питающие, силовые и другие системы техники, подвергаются воздействию колебаний давления, импульсных нагрузок, действия углеводородных жидких сред и климатических факторов с температурным интервалом, превышающем $120{ }^{\circ} \mathrm{C}$. Резины, пригодные для использования в условиях холодного климата, должны иметь высокую морозостойкость вплоть до $-55-65{ }^{\circ} \mathrm{C}$, высокий уровень прочностных свойств, повышенные релаксационные свойства, стойкость в агрессивных углеводородных средах и высокие триботехнические характеристики [1]. В связи с этим актуальность представляет опробование новых рецептур резин с заданным комплексом свойств, содержащих эффективные модификаторы и наполнители.

\section{2. Материал и методика}

В качестве эластомерной основы предложен пропиленоксидный каучук (СКПО, ТУ 2294-067-16810126-99), обладающий уникальной морозостойкостью $\left(\mathrm{T}_{\mathrm{c}}=-74{ }^{\circ} \mathrm{C}\right)$, озоно- и термостойкостью [2]. Однако для удовлетворения всех требований, предъявляемых к уплотнительным резинам, необходимо повысить остаточную деформацию сжатия, масло- и износостойкость СКПО. Для достижения данных целей эластомер совмещали с ультрадисперсным политетрафторэтиленом и сравнивали с результатами, полу- 
ченными при разработке материалов на основе данного каучука с традиционным фторопластом Ф-4, на изобретение которого авторами получен патент РФ [3].

Ультрадисперсный политетрафторэтилен (УПТФЭ, ТУ 2229-004-02698192-2002) обладает агрессивостойкостью в сочетании с высокой термостойкостью, низким коэффициентом трения и высокими триботехническими характеристиками, присущими традиционному ПТФЭ Ф-4, а также повышенной адгезией к металлическим поверхностям и частичной растворимостью полимера. УПТФЭ применяют в качестве присадки в масла, при этом частицы фторполимера прочно связываются с поверхностью металла и заполняют неровности плотной пленкой. Эта пленка приводит к резкому уменьшению коэффициента трения между металлическими поверхностями и защищает их от износа и коррозии [4]. Такой же механизм поверхностного действия следует ожидать и при введении его в резиновые смеси на основе СКПО.

Композиции на основе СКПО, содержащие от 0,5 до 20 мас. ч. УПТФЭ, готовили в пластикордере «BRABENDER PL-2200-3». Основные технические характеристики определяли согласно стандартным методикам (ГОСТ 270-84, ГОСТ 9.029-74, ГОСТ 408-78, ГОСТ 9.030-74). В качестве агрессивных сред были отобраны масла МС-8П (масло 1), СМ-4,5 (масло 2), МС-20 (масло 3), а также нефть Талаканского (нефть ТМ) и Иреляхского месторождений (нефть ИМ). Износостойкость смесей оценивали на приборе АР-40 по методу определения сопротивления истиранию. Структуру материалов исследовали с помощью электронного сканирующего микроскопа JSM - 6480LV фирмы «JEOL», снабженного рентгеноспектральной приставкой «Oxford».

\section{3. Результаты и обсуждение}

Введение ультрадисперсного политетрафторэтилена в матрицу пропиленоксидного каучука приводит к улучшению износостойкости на $35 \%$, снижению остаточной деформации сжатия на $11 \%$ и повышению коэффициента морозостойкости при $-50{ }^{\circ} \mathrm{C}$ на 12 \% при малых дозировках наполнителя. Оптимальными свойствами обладают композиции, содержащие 0,5-1 мас. ч. УПТФЭ. При этом введение УПТФЭ наиболее предпочтительно по сравнению с введением фторопласта $\Phi-4$, так как для достижения положительного эффекта в резиновую смесь достаточно ввести 0,5-1 мас. ч. УПТФЭ против 20 мас. ч. традиционного $[3,5]$.

Исследования на стойкость к воздействию жидких агрессивных сред свидетельствуют об удовлетворительном уровне маслостойкости для резин уплотнительного назначения (рис. 1). При этом в масле 1 и 3 наблюдается тенденция к снижению степени набухания при малых дозировках фторполимерного компонента до $20 \%$.

Для изучения изменения свойств композитов методом электронной микроскопии исследовали порошки политетрафторэтилена Ф-4 и УПТФЭ, исходную резиновую смесь на основе СКПО, а также смеси СКПО с фторполимерами. На микрофотографиях (рис. 2) видно, что при введении в пропиленоксидную матрицу как ПТФЭ Ф-4, так и УПТФЭ сохраняют структуру, свойственную для неспеченного политетрафторэтилена. Поскольку переработка фторопласта Ф-4 осуществляется при температурах выше $370{ }^{\circ} \mathrm{C}$, УПТФЭ - выше $232{ }^{\circ} \mathrm{C}$, а температура вулканизации резиновой смеси не превышает $150{ }^{\circ} \mathrm{C}$, то исходная структура фторопласта, состоящая из сферолитоподобных частиц, сохраняется и в эластомерных композициях. 
ittp.///ream-journal.0in]

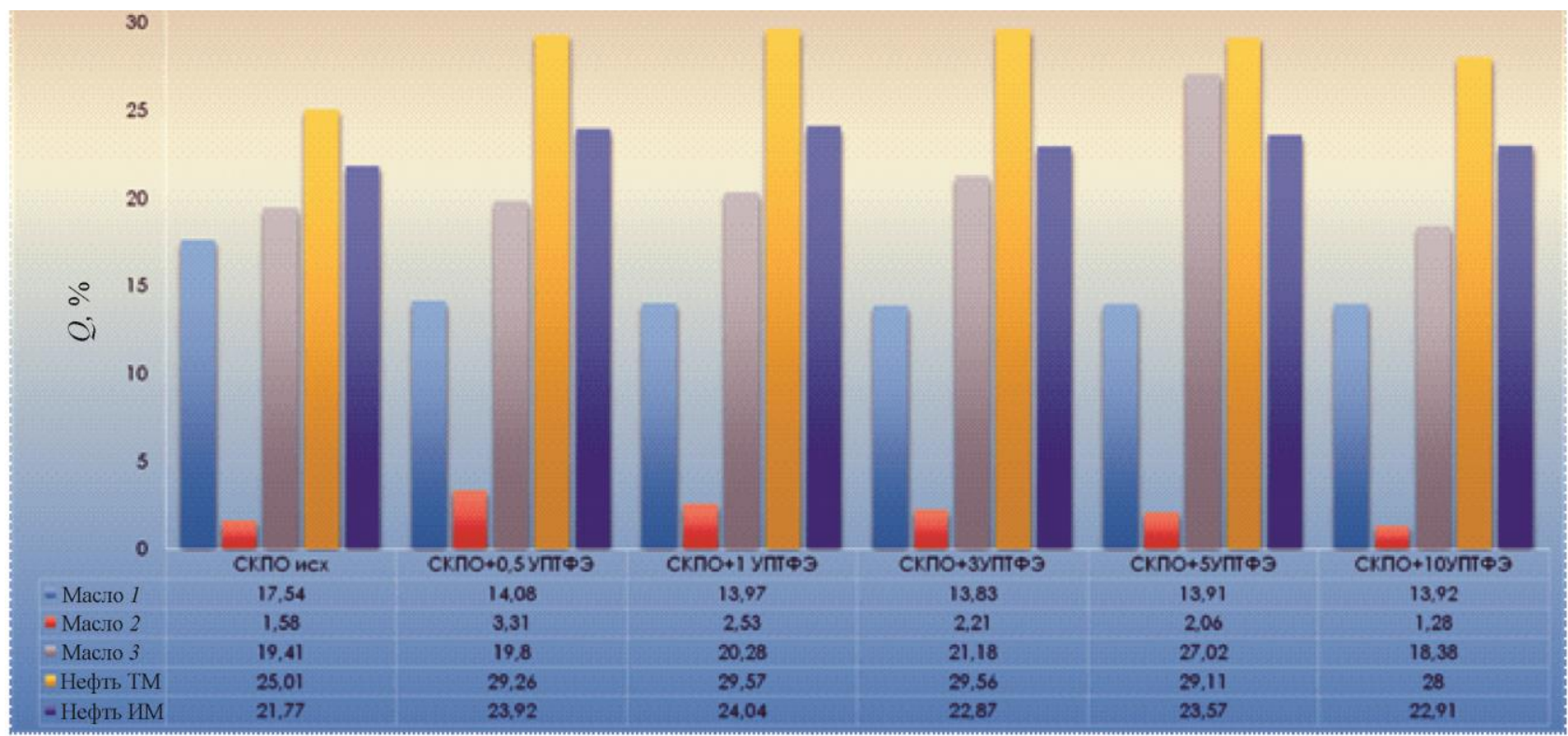

Рис. 1. Зависимость значений степени набухания резин на основе СКПО в различных агрессивных средах (масло 1 - МС-8П; масло 2 - СМ-4,5, масло 3 - МС-20, нефть ТМ - нефть Талаканского месторождения, нефть ИМ - нефть Иреляхского месторождения) от содержания фторполимера

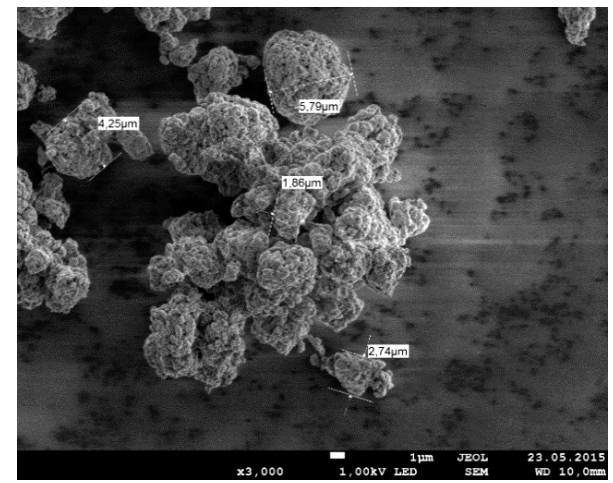

$a$

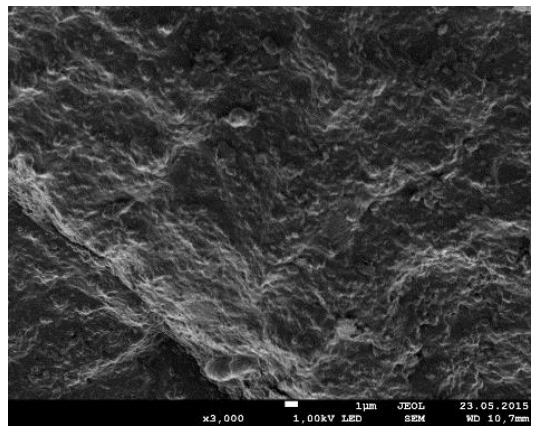

B

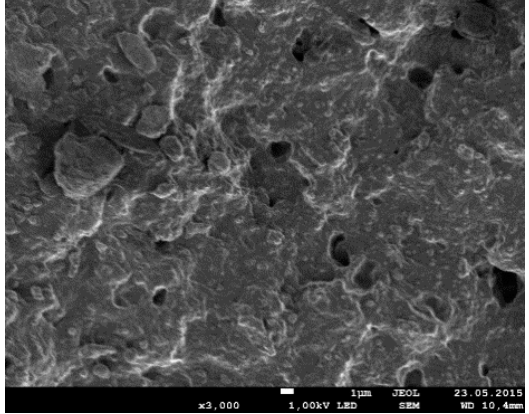

2

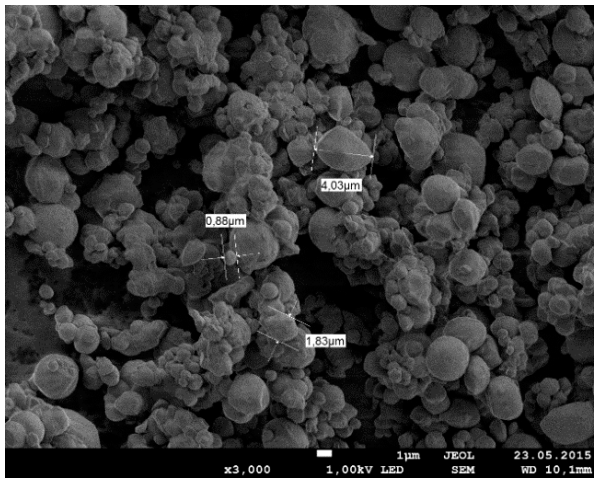

$\sigma$

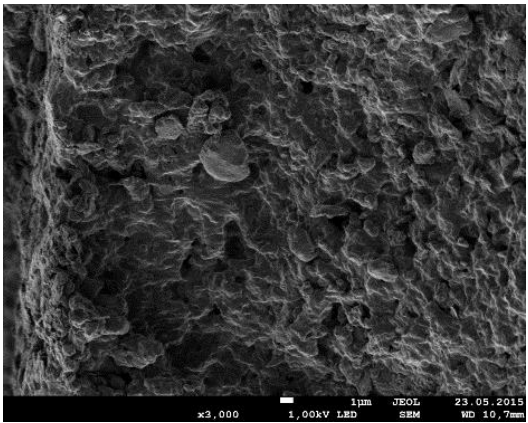

$\partial$

Рис. 2. Электронные микрофотографии при увеличении ×3000: $a-\Phi-4 ; \sigma-$ УПТФЭ; в - исходной резиновой смеси на основе СКПО; 2 - резин на основе СКПО + 10 мас. ч. ПТФЭ Ф-4; $\partial$ - резин на основе СКПО+10 мас. ч. УПТФЭ 
Данные рентгеноспектрального анализа образцов резин на основе СКПО и 1 мас. ч. УПТФЭ показали, что в объеме частицы фторполимера, представляющие дисперсную фазу, распределены достаточно равномерно (по элементу F и O). Размер локальных скоплений частиц не превышает 10 мкм (рис. 3). При больших содержаниях УПТФЭ размер частиц увеличивается до 40 мкм вследствие агломерации. В композициях, содержащих Ф-4, распределение полимера также равномерное, размер частиц добавки составляет 55 мкм. Частицы фторполимера как Ф-4, так и УПТФЭ располагаются в некоторых микрообластях, что свидетельствует о слабом межфазном взаимодействии между фазами полимеров [6].
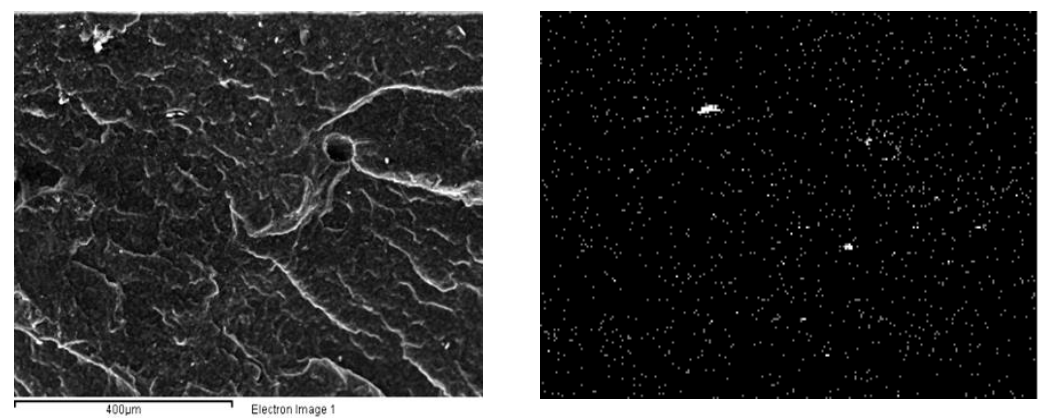

$\mathrm{F}$

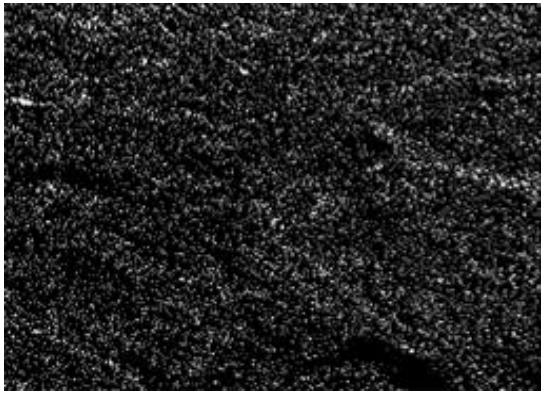

$\mathrm{O}$

Рис. 3. Карта распределения химических элементов (фтор, кислород) в объеме образца композиции на основе СКПО+1 мас. ч. УПТФЭ при увеличении $\times 50$

Исследования суммарных спектров (рис. 4) и количественный микроанализ поверхности и объема образцов резин, показали, что на поверхности резины содержание фтора больше, чем в объеме материала. Следовательно, частицы УПТФЭ в композициях его содержащих, в основном концентрируются на поверхности резин. Справочные данные поверхностного натяжения (у) и поверхностной энергии подтверждают полученные данные (у рассчитанного по контактному углу близких по строению веществ: $\sigma$ ПТФЭ $=19 \mathrm{mH} / \mathrm{m} ; \sigma$ полиоксипропилена $=32 \mathrm{mH} / \mathrm{M}$ ) [7], т. е. компонент, обладающий более низким значением $\sigma$ в жидких системах, мигрирует на поверхность материала.

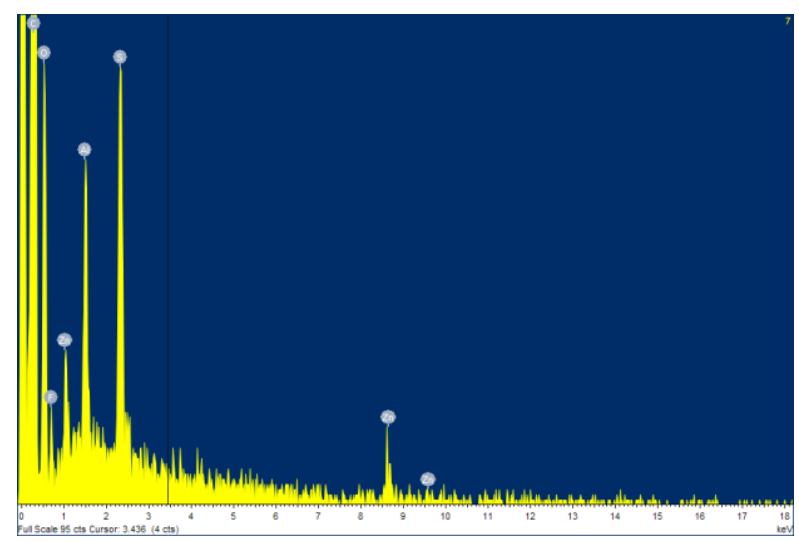

$a$

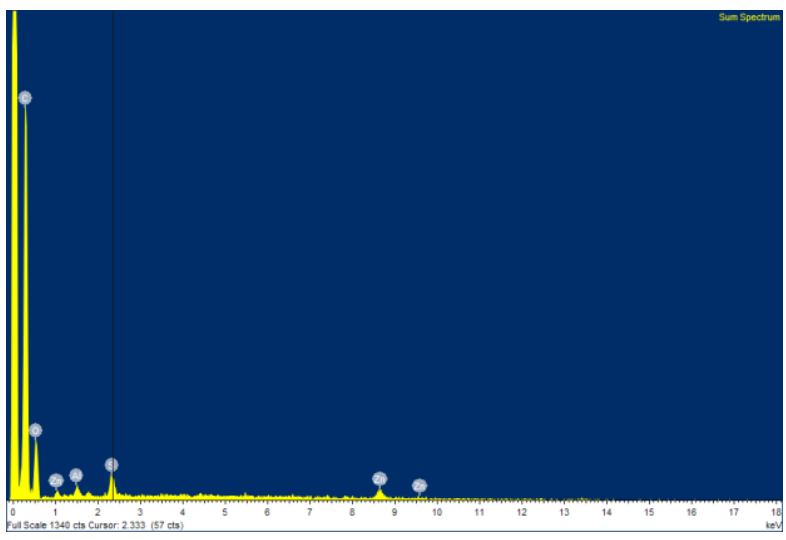

$\sigma$

Рис. 4. Спектры содержания элементов (углерод, кислород, фтор, алюминий, сера, цинк) на поверхности $(a)$ и в объеме $(б)$ образца СКПО + 1 мас. ч. УПТФЭ при увеличении $\times 800$ 


\section{4. Заключение}

Проведенные исследования показали, что для достижения положительного эффекта на свойства материала в резиновую смесь достаточно ввести 0,5-1 мас. ч. наполнителя на 100 мас. ч. каучука. В то время как в проведенных нами ранее исследованиях по совмещению СКПО с фторопластом Ф-4 оптимальная дозировка составляла 20 мас. ч. [3, 5]. Исследования на стойкость к воздействию жидких агрессивных сред (различные масла, нефть) свидетельствуют об удовлетворительном уровне маслостойкости для резин уплотнительного назначения. Снижение содержания УПТФЭ связано с высокой активностью его частиц, их наноструктурной организацией, лучшей равномерностью распределения в объеме эластомерной матрицы. Малое взаимодействие фаз вследствие разности значений поверхностного натяжения и поверхностной энергии приводит к их сегрегации в объеме и на поверхности материала, причем значительная часть частиц УПТФЭ концентрируется на поверхности материала. Наличие частиц полимера с низким коэффициентом трения, обладающего способностью прочно связываться металлом и заполнять неровности пленкой, способствует защите уплотнительного материала при эксплуатации. На данные составы получен патент Российской Федерации и патент США $[12,13]$. Разработанные материалы уплотнительного назначения рекомендуются к использованию для экстремальных условий эксплуатации.

\section{Благодарность}

Результаты были получены в рамках выполнения государственного задания Минобрнауки России № 11.7295.2017/7.8.

\section{Литература}

1. Черский И. Н. Полимерные материалы в современной уплотнительной технике. Якутск : Книжное издательство, 1975. - 110 с.

2. Разработка атмосферостойких резин с улучшенными низкотемпературными и адгезионными свойствами / О. А. Говорова, А. С. Вишницкий, Г. В. Чубарова, Ю. Л. Морозов // Каучук и резина. - 1999. - № 2. - С. 18-20.

3. Износостойкая смесь на основе пропиленоксидного каучука : пат. 2294346 Рос. Федерация / Петрова Н. Н., Портнягина В. В., Биклибаева Р. Ф., ИПНГ СО РАН, ООО «Нордэласт». - № 2005115404/04 ; заявл. 20.05.2005 ; опубл. 27.02.2007. Бюл. № 6. - 4 с.

4. Бузник В. М., Фомин В. М., Алхимов А. П. Металлополимерные нанокомпозиты. Новосибирск : Изд-во СО РАН, 2005. - 260 с.

5. Петрова Н. Н., Портнягина В. В. Резины на основе смесей пропиленоксидного каучука и политетрафторэтилена // Каучук и резина. - 2007. - № 4. - С. 8-11.

6. Кулезнев В. Н. Смеси полимеров. - М. : Химия, 1980. - 304 с.

7. Ван Кревелен Д. В. Свойства и химическое строение полимеров / под. ред. А. Я. Малкина. - М. : Химия, 1976. -414 с.

8. Износостойкая резина на основе пропиленоксидного каучука и ультрадисперсного политетрафторэтилена : пат. 2502759 Рос. Федерация / Петрова Н. Н., Портнягина В. В., ИПНГ СО РАН, СВФУ им. М. К. Аммосова. - № 2012119320/05 ; заявл. 11.05.2012. ; опубл. 27.12.2013. Бюл. № 36. -4 c.

9. Wear-resistant rubber based on propyleneoxide rubber and ultrafine polytetrafluoroethylene : пат. US 8841370 B1 / Petrova N. N., Portnyagina V. V., NEFU, Science Institute of Oil and Gas Problems of SB RAS. - № 13/889,500 ; appl. filed May 8, 2013 ; September 23, 2014. - 6 p. 